\title{
Programa Mais Médicos: revisão crítica da implementação sob a perspectiva do acesso e universalização da atenção à saúde
}

\author{
More Doctors Program: a critical review of the implementation \\ from the perspective of access and the universalization of health care
}

Marco Antonio Separavich (https://orcid.org/0000-0001-7703-344X) ${ }^{1}$

Marcia Thereza Couto (https://orcid.org/0000-0001-5233-4190) ${ }^{1}$

${ }^{1}$ Departamento de Medicina Preventiva, Faculdade de Medicina, Universidade de São Paulo. Av. Dr. Arnaldo $455,2^{\circ}$ andar. 01246903. São Paulo SP Brasil. mseparavich@hotmail.com

\begin{abstract}
The scope of this critical narrative review is the analysis of the national literature on the implementation of the More Doctors Program (PMM), from January 2016 to May 2019, distributed according to its three programmatic aspects: 1. Improvement of Infrastructure of the Primary Health Care Networks; 2. Expansion of Vacancies and Courses in Medicine and the Reform of Medical Education; and 3. Emergency Medical Supplies. After consulting the Scielo and Lilacs databases through the key words Programa Mais Médicos, and the English and Spanish equivalents, 37 articles were located, of which 31 were selected because they focused specifically on the implementation of one or more aspects. Aspect 1 had the lowest number of publications, while the highest concentration of articles occurred in aspects 2 and 3, in 2016 and 2019, respectively, depending on the timely implementation of the PMM. The literature analyzed points to successes and weaknesses in the formulation and implementation of the Program. This should be taken into consideration in the elaboration and execution of future projects, based on the expansion of access and the universalization of medical care to vulnerable populations. Key words Review, Public health policy, More Doctors Program, Primary health care
\end{abstract}

Resumo Trata-se de uma revisão narrativa crítica que analisa a literatura nacional sobre a implementação do Programa Mais Médicos (PMM), no período de janeiro de 2016 a maio de 2019, distribuída segundo os três eixos programáticos que o compõem: 1) melhoria da infraestrutura das redes de atenção básica à saúde; 2) ampliação de vagas e cursos de medicina e reformas na educação médica; e 3) provisionamento emergencial médico. Consultada as fontes informacionais Scielo e Lilacs, mediante os marcadores Programa Mais Médicos, e suas versões em inglês e espanhol, encontraram-se 37 artigos, dos quais 31 foram selecionados, por se centrarem especificamente na implementação de um ou mais eixos. O eixo 1 apresentou menor número de publicações, enquanto a maior concentração de artigos se deu nos eixos 2 e 3, nos anos de 2016 e 2019, respectivamente, consoante à implementação temporal do PMM. A literatura analisada aponta êxitos e fragilidades na formulação e implementação do programa, devendo ser considerados na elaboração e execução de projetos futuros, tendo por base a ampliação do acesso e a universalização do atendimento médico às populações vulneráveis.

Palavras-chave Revisão, Políticas públicas de saúde, Programa Mais Médicos, Atenção primária à saúde 


\section{Introdução}

Segundo estudo sobre a distribuição de médicos no país, com dados obtidos em fontes informacionais de registro médico (conselhos Regional de Medicina - CRM - e Federal de Medicina CFM -, Comissão Nacional de Residência Médica - CNRM - e Associação Médica Brasileira - AMB), além de questionários estruturados disponibilizados via plataforma on-line aos médicos recém-formados por ocasião do registro no CRM, até janeiro de 2018 o Brasil contava com 452.801 médicos, à razão de 2,18 médicos por mil habitantes ${ }^{1}$.

O estudo aponta a distribuição desigual desses profissionais no território nacional, tendo em seus extremos Vitória (ES), com 12 médicos por mil habitantes, e municípios do Norte e Nordeste do país que sequer atingem a razão de 1 médico por mil habitantes.

$\mathrm{O}$ estudo também indica o aprofundamento dessa desigualdade quando observada a densidade médica nas capitais e no interior de todas as regiões do país, registrando a razão de 5,07 médicos por mil habitantes nas regiões metropolitanas e 1,28 no interior ${ }^{1}$. A distribuição desigual dos médicos, tal como indicada, contribui para acentuar iniquidades estruturais no Sistema Único de Saúde (SUS).

No relatório sobre os 30 anos do SUS, a Organização Pan-americana de Saúde (OPAS) aponta conquistas, desafios e tece recomendações estratégicas para a diminuição das desigualdades em Saúde no SUS até 2030, em conformidade com os Objetivos de Desenvolvimento Sustentável para o Milênio, das Nações Unidas, compromisso do qual o Brasil é partícipe, além de vários países latino-americanos. À OPAS coube organizar agenda com uma série de ações, tendo como valor central diretivo a consolidação do direito universal à saúde. São reiterados os princípios de integralidade, universalidade e equidade que sustentam o SUS, não obscurecendo, entretanto, a necessidade de reformas incrementais, sobretudo nas relações interfederativas, público-privadas e no modelo de financiamento ${ }^{2}$.

No que tange ao acesso da população, representado pela disponibilidade de recursos humanos para o SUS, questão central para garantir a universalidade e a integralidade na cobertura dos serviços, o relatório indica a carência contínua de médicos em áreas economicamente menos desenvolvidas e a necessidade de fortalecer o modelo da atenção primária à saúde (APS), visando garantir a universalização do acesso. Destacam-se a Estratégia Saúde da Família e a implementação do Programa Mais Médicos como promotores da elevação da taxa de cobertura para $70 \%$ da população exclusivamente dependente do SUS, realidade evidenciada nas áreas de maior vulnerabilidade social do país ${ }^{2}$.

Criado mediante a Medida Provisória $621 / 2013$, posteriormente convertida na Lei ${ }^{\circ}$ 12.871, de outubro de 2013³, o Programa Mais Médicos (PMM) se consubstancia num pacto interfederativo envolvendo as três esferas de gestão do SUS, objetivando a melhoria do atendimento à saúde dos usuários do sistema, sobretudo das populações social e sanitariamente vulneráveis, que sofrem com a ausência ou a permanência intermitente de profissionais médicos nos serviços ${ }^{4}$.

Estrutura-se em três eixos estratégicos: (1) melhoria da infraestrutura das redes de atenção à saúde, principalmente da APS, porta de entrada principal dos cidadãos aos serviços de saúde no país; (2) ampliação de vagas e cursos de medicina, com reformas na educação médica, na graduação e na residência; e (3) Projeto Mais Médicos para o Brasil (PMMB), com o provisionamento emergencial de médicos brasileiros e estrangeiros em áreas prioritárias, isto é, locais em que a APS é deficiente ou escassa de serviços médicos.

Da perspectiva longitudinal, a implementação do eixo 3 do PMM busca garantir, no curto prazo, o acesso aos serviços médicos das populações socialmente vulneráveis, com a diminuição da rotatividade desses profissionais e a consequente redução da demanda espontânea. Por sua vez, a médio e longo prazos, a implementação do eixo 1 se projeta como incremento da qualidade da atenção, tanto nos aspectos materiais das unidades de saúde quanto na distribuição e organização uniformes das equipes de saúde, assim como na regularidade dos cuidados. Da mesma forma, a implementação do eixo 2 objetiva garantir a formação local de médicos nas regiões distantes, privilegiando a Residência de Medicina de Família e Comunidade e o conhecimento das morbidades prevalentes na região, com vistas ao fortalecimento da APS, gerando melhoria do acesso, do atendimento e da economia de recursos aos municípios ${ }^{2}$.

O PMM registrou, até o ano de 2018, o incremento de 18.500 médicos na $\mathrm{APS}^{2}$, sendo 79\% de origem cubana, conforme estabelecido em convênio internacional entre os ministérios da Saúde de Cuba e Brasil e a OPAS 5 .

Estudos apontam que o PMM se mostrou promissor, sobretudo na ampliação do acesso das populações desassistidas dos serviços médicos 
e cuidados de saúde efetivados por esses profissionais, registrando a diminuição da escassez de médicos historicamente registrada em regiões carentes ${ }^{6-10}$. Em relação à formação médica e à implementação de novos cursos de medicina, destacam-se as experiências exitosas de interiorização, principalmente no Norte e Nordeste do país, regiões em que a carência desses profissionais é mais sentida ${ }^{11,12}$.

A despeito do reconhecido êxito do progra$\mathrm{ma}^{13,14}$, em 14 de novembro de 2018, o governo de Cuba, por meio de nota emitida por seu Ministério da Saúde Pública, anunciou a retirada dos profissionais médicos cubanos do $\mathrm{PMM}^{15}$. A saída da cooperação foi justificada pelas autoridades cubanas como reação ao descumprimento de garantias acordadas no início do convênio e à imposição de condições inaceitáveis aos profissionais cubanos pelo governo brasileiro, expressas pelo então recém-eleito presidente Jair Bolsonaro.

Entre as alterações propostas para o novo acordo, o governo brasileiro exigia a realização da prova de habilidades clínicas dos médicos cubanos (Revalida) para continuarem a atuar profissionalmente, além de cortar o repasse do percentual de seus salários ao governo de Cuba, como anteriormente acordado. No que pese a competência dos médicos intercambistas, atestada favoravelmente nos estudos indicados acima, o fato se revelou como desconfiança do governo brasileiro quanto à formação daqueles médicos, atitude apontada e rechaçada pelo governo cubano ${ }^{16}$. A saída de Cuba impactou negativamente a manutenção do PMM, uma vez que, quase em sua totalidade, os médicos intercambistas eram de origem cubana.

Desvelar as fragilidades e os pontos exitosos do programa para a elaboração e implementação de projetos futuros que visem o avanço e a sustentação da APS no SUS, baseados na ampliação do acesso e na universalização do atendimento médico às populações vulneráveis, tem sido o objetivo de alguns autores ${ }^{16}$. Dessa forma, este estudo tenciona apresentar as contribuições do PMM em seus três eixos de implementação, tematizadas segundo o acesso e a universalização da atenção, conforme os estudos apresentados na literatura nacional sobre o assunto. Expõem-se, assim, suas potencialidades e deficiências para a efetiva diminuição das desigualdades de saúde no SUS, objetivo principal em que se baseou a elaboração do programa.

\section{Metodologia}

Trata-se de uma revisão narrativa crítica. Para tanto, consultou-se as seguintes fontes informacionais: Scielo, integrante da Biblioteca Virtual em Saúde (BVS), e LILACS, Literatura Latino-Americana e do Caribe em Ciências da Saúde, ambas agregadoras dos periódicos mais consultados e de maior expressão científica da região no campo da saúde pública coletiva, além de disponibilizarem acesso gratuito e na íntegra aos artigos.

O recorte temporal estabelecido cobriu o período de janeiro de 2016 a maio de 2019, visto que em duas revisões anteriores ${ }^{14,17}$ mapeou-se a produção científica sobre a implementação do Programa Mais Médicos no período 2013-2016. A busca se deu em maio de 2019 e utilizou os descritores: Programa Mais Médicos, em inglês Mais Médicos Program e/ou More Doctors Program e em espanhol Programa Más Médicos.

Para a seleção dos artigos a partir dos títulos e resumos, foram utilizados os seguintes critérios de inclusão: 1) artigos publicados em língua portuguesa no período de 2016 a 2019;2) artigos produzidos por pelo menos um/a pesquisador/a brasileiro/a; 3 ) artigos cujos estudos foram realizados com materiais empíricos oriundos de contextos brasileiros, ou de reflexão teórica, ou ainda de revisão da literatura sobre o tema; 4) artigos com acesso a texto completo em meio digital; e 5) apresentar avaliação de pelo menos um dos três eixos de estruturação do PMM. Foram excluídos os 29 artigos que apareceram de forma repetida.

Embora a literatura cinzenta não tenha entrado no escopo da revisão, compreende-se que a mesma foi em parte contemplada neste estudo. Cinco artigos compilados e analisados são derivados de trabalhos desenvolvidos no âmbito da pós-graduação em Ciências da Saúde e Saúde Pública dos primeiros autores, respectivamente, duas teses de doutorado ${ }^{17,18}$, duas dissertações de mestrado ${ }^{5,19}$ e uma monografia de residência multiprofissional em Saúde Coletiva ${ }^{20}$. Quanto à literatura técnica, um artigo sintetizou os resultados de estudos para subsidiar a melhoria do $\mathrm{PMM}^{14}$, consubstanciando-se em informe técnico da OPAS, além do Relatório Técnico amplo da $\mathrm{OPAS}^{2}$.

Os artigos foram lidos exaustivamente, tematizados segundo o acesso e a universalização da atenção e distribuídos nos três eixos estratégicos do PMM. 


\section{Resultados}

Foram selecionados 37 artigos: 14 publicados na revista Ciência \& Saúde Coletiva, da Associação Brasileira de Saúde Coletiva (ABRASCO); 17 na revista Interface, editada pela Universidade Estadual Paulista (UNESP), Faculdade de Medicina de Botucatu; dois na Revista Trabalho Educação e Saúde, da Fundação Osvaldo Cruz, Escola Politécnica de Saúde Joaquim Venâncio; um na Revista Brasileira de Educação Médica, publicada pela Associação Brasileira de Educação Médica; um na Saúde em Debate, do Centro Brasileiro de Estudos de Saúde; um na Caderno $C R H$, da Universidade Federal da Bahia, Faculdade de Filosofia e Ciências Humanas; e um na Revista Pan -americana de Salud Pública, editada pela OPAS.

As duas revistas científicas com maior concentração de artigos dedicaram números exclusivos aos estudos analíticos sobre a implementação do PMM: Ciência \& Saúde Coletiva, em setembro de 2016; e Interface (Botucatu), em dezembro de 2017 e maio de 2019. Os artigos encontrados foram classificados segundo os eixos estruturantes e implementadores do programa, conforme o Quadro 1. Seis artigos ${ }^{13,14,16,21,22,23}$, embora presentes na revisão e discussão, não constam do quadro, pois não avaliam, eminentemente, a implementação dos eixos estratégicos previstos, resultando no total de 31 artigos distribuídos nos eixos programáticos.

A distribuição dos estudos nos eixos programáticos se deu pela análise dos seus conteúdos, conforme tematizados nesta revisão. Assim, estudos que analisaram concomitantemente a implementação do PMM em mais de um dos seus eixos foram alocados naquele em que a sua contribuição pode complementar de maneira mais significativa.

Com relação ao número de artigos distribuídos por eixo programático para o período observado, o eixo 1, referente à melhoria da infraestrutura das redes de atenção básica à saúde, apresentou o menor número de publicações: quatro. Os eixos 2 e 3 concentraram a maioria dos estudos, 13 e 14, respectivamente (Quadro $1)$.

Atentando-se às publicações por eixo programático, segundo a distribuição no tempo observado, verificou-se que as publicações que analisaram a implementação do eixo 1 do programa se concentraram no ano de 2016: três. Já os demais eixos apresentaram concentração de artigos de forma inversamente proporcional entre si: enquanto os estudos de implementação do eixo 3, provisionamento emergencial da atenção médica, se avolumaram no ano de 2016, oito, os do eixo 2, referentes à ampliação de vagas e cursos de medicina e reformas na educação médica, tiveram ascensão em 2019: seis (Gráfico 1). Dado o caráter emergencial da implantação do eixo 3 e os resultados de médio prazo passíveis de serem analisados para o eixo 2, infere-se que as diferenças observadas na concentração dos estudos desses eixos no período estudado refletem a diferença temporal na implementação de cada um deles, incidindo, consequentemente, na quantidade das publicações selecionadas sobre o PMM.

\section{Discussão}

\section{Acesso e universalização da atenção à saúde}

\section{Eixo melhoria da infraestrutura das redes de atenção básica à saúde}

Neste eixo, as investigações centram-se na análise estrutural e nas condições de trabalho dos médicos participantes, comparando sobretudo as condições de acessos e serviços inter-regionais.

Soares Neto, Machado e Alves ${ }^{24}$ analisam a infraestrutura das Unidades Básicas de Saúde relacionando-a ao índice de desenvolvimento humano municipal (IDHM), a partir de dados do Programa Nacional de Melhoria do Acesso e da Qualidade da Atenção Básica (PMAQ), de 2012. Os autores apuraram que os níveis mais baixos de infraestrutura se encontram nas regiões Norte e Nordeste do país, unidades com alocação de médicos pelo PMM, contrapondo-se ao nível mais elevado registrado na região Sudeste, ratificando a situação histórica de precariedade daquelas regiões na oferta e acesso aos serviços de saúde.

Dessa forma, ressaltam que o PMM é efetivo na redução das iniquidades em saúde, viabilizando o direito à saúde, com o compromisso dos municípios participantes de aderirem ao Programa Requalifica UBS, o que obriga a alocação de recursos financeiros na construção e reforma das Unidades Básicas de Saúde, prevendo-se um total de 26 mil UBS, distribuídas por 5 mil municípios $^{25}$. Já o índice IDHM está relacionado ao crescimento do nível de infraestrutura das UBS, sobretudo quanto a educação e renda ${ }^{24}$.

Giovanella e colaboradores ${ }^{26}$ destacam que a qualidade da infraestrutura das UBS se reflete no processo de trabalho, na satisfação profissional, facilitando a melhoria da atenção à saúde da população e a fixação dos médicos nos serviços. Embora os autores ratifiquem a importância do 
Quadro 1. Artigos selecionados sobre o PMM, segundo os eixos programáticos, autoria (sobrenome do primeiro autor), ano de publicação e nome da revista científica

\begin{tabular}{|c|c|c|c|}
\hline Eixos Programáticos & $\begin{array}{r}\text { Autoria } \\
\end{array}$ & Ano de publicação & Nome da revista científica \\
\hline \multirow{4}{*}{$\begin{array}{l}\text { 1. Melhoria da infraestrutura } \\
\text { das redes de atenção básica } \\
\text { à saúde }\end{array}$} & Giovanella ${ }^{26}$ & 2016 & Cien Saude Colet \\
\hline & Soares Neto ${ }^{24}$ & 2016 & Cien Saude Colet \\
\hline & Comes $^{27}$ & 2016 & Cien Saude Colet \\
\hline & Pinto $^{25}$ & 2017 & Interface (Botucatu) \\
\hline \multirow{13}{*}{$\begin{array}{l}\text { 2. Ampliação de vagas, } \\
\text { cursos de medicina e } \\
\text { reformas na educação } \\
\text { médica }\end{array}$} & Alencar $^{31}$ & 2017 & Interface (Botucatu) \\
\hline & Barreto $^{33}$ & 2019 & Interface (Botucatu) \\
\hline & Freire Filho ${ }^{34}$ & 2018 & Interface (Botucatu) \\
\hline & Silva $a^{38}$ & 2019 & Trab Educ Saude \\
\hline & Silva Junior ${ }^{28}$ & 2016 & Cien Saude Colet \\
\hline & Storti $\mathrm{i}^{35}$ & 2017 & Interface (Botucatu) \\
\hline & Melo $^{11}$ & 2017 & Interface (Botucatu) \\
\hline & Oliveira ${ }^{29}$ & 2019 & Trab Educ Saude \\
\hline & Oliveira $^{30}$ & 2019 & Interface (Botucatu) \\
\hline & Oliveira $^{12}$ & 2017 & Interface (Botucatu) \\
\hline & Pinto $^{37}$ & 2019 & Interface (Botucatu) \\
\hline & Sordi $^{32}$ & 2019 & Interface (Botucatu) \\
\hline & Villa Real $^{36}$ & 2017 & Rev Bras Educ Med \\
\hline \multirow{14}{*}{$\begin{array}{l}\text { 3. Projeto Mais Médicos para } \\
\text { o Brasil (PMMB) }\end{array}$} & Almeida $^{21}$ & 2017 & Interface (Botucatu) \\
\hline & Comes $^{41}$ & 2016 & Cien Saude Colet \\
\hline & Girardi $^{10}$ & 2016 & Cien Saude Colet \\
\hline & Girardi $^{6}$ & 2016 & Cien Saude Colet \\
\hline & Herval $^{9}$ & 2017 & Interface (Botucatu) \\
\hline & Kemper $^{17}$ & 2016 & Cien Saude Colet \\
\hline & Lima $^{7}$ & 2016 & Cien Saude Colet \\
\hline & $\mathrm{Liz}^{40}$ & 2017 & Interface (Botucatu) \\
\hline & Nogueira $^{20}$ & 2016 & Cien Saude Colet \\
\hline & Oliveira $^{8}$ & 2016 & Cien Saude Colet \\
\hline & Pereira $^{18}$ & 2017 & Interface (Botucatu) \\
\hline & Soares $^{19}$ & 2017 & Interface (Botucatu) \\
\hline & $\operatorname{Rech}^{42}$ & 2018 & Rev Panam Salud Publica \\
\hline & Telles $^{43}$ & 2019 & Cad $\mathrm{CRH}$ \\
\hline
\end{tabular}

Fonte: Elaborado pelos autores.

Requalifica UBS como um dos fatores significativos para a fixação dos profissionais médicos na APS e, consequentemente, o fortalecimento do direito à saúde, como apontado no estudo anterior, reconhecem que o provimento estratégico de médicos, mesmo que emergencial, ampliou o acesso da população aos serviços de saúde, além de contribuir para a regularidade da permanência do profissional médico nas equipes da atenção básica, ainda que por um prazo determinado.

Entretanto, observam que as UBS em piores condições são as que menos participam dos programas, enfraquecendo o potencial redutor das iniquidades no acesso aos recursos de saúde. É na região Nordeste que essas UBS se concentram, havendo a necessidade da convergência do PMM e do Requalifica UBS, entre outros programas, nessas localidades, a fim de ampliar as equipes e o acesso aos serviços de saúde das populações mais vulneráveis ${ }^{26}$.

O estudo de Comes e colaboradores ${ }^{27}$, embora não se dedique à análise da infraestrutura das UBS, tangencia algumas questões pertinentes à infraestrutura, referindo-se ao acesso aos serviços e à responsividade dos municípios inscritos no PMM, segundo a avaliação dos usuários. Trata-se de estudo descritivo, realizado em 32 municípios considerados pequenos, longínquos e pobres, com 263 usuários dos serviços de saúde. Buscouse apreender, aplicando-se um questionário com 


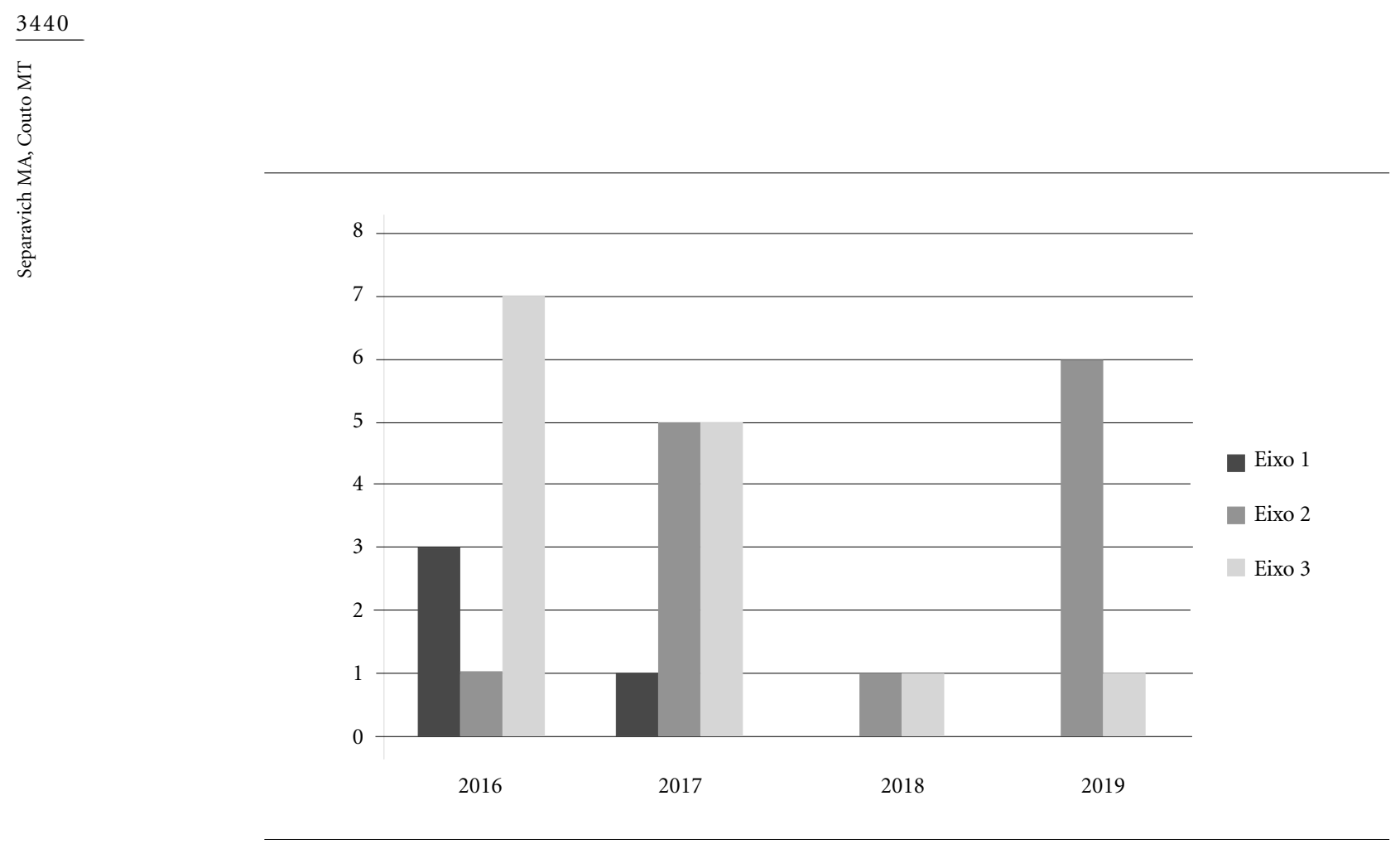

Gráfico 1. Distribuição temporal dos artigos científicos selecionados, segundo o eixo programático.

Fonte: Elaborado pelos autores.

perguntas abertas e fechadas, a satisfação desses usuários quanto ao atendimento médico e às informações sobre doenças e tratamentos.

Sobre a dimensão da responsividade, termo cunhado pela Organização Mundial da Saúde (OMS) para se referir à capacidade de resposta do bom desempenho dos sistemas de saúde ${ }^{27}$, apurou-se que os usuários estavam satisfeitos com o atendimento médico, bem como demonstraram contentamento com os aspectos não médicos do cuidado: rapidez no agendamento das consultas, tempo de espera inferior a uma hora e resguardo da privacidade.

O resultado positivo da avaliação dos usuários da infraestrutura dos serviços, entretanto, não impediu que sugerissem melhorias na estrutura da UBS, mais medicamentos disponíveis e maior presença de médicos.

\section{Eixo ampliação de vagas e cursos de} medicina e reformas na educação médica

As análises dos estudos neste eixo apontam a importância que a expansão do número de profissionais formados em medicina têm para a APS, dados o caráter provisório e emergencial do PMMB e a necessidade de formação e fixação de médicos brasileiros em localidades precárias e distantes. Ressaltamos avanços tanto na expansão dos cursos de graduação de medicina e na ampliação de vagas para a residência de Medicina de Família e Comunidade (MFC) quanto na adoção de práticas pedagógicas que proporcionam o contato e a vivência do futuro médico com os segmentos sociais rural e periférico das grandes cidades. Essas ações qualificam o acesso da população à atenção de saúde humanizada, afinada com as suas necessidades de saúde e com a universalização do atendimento.

A lei que instituiu o PMM, em seu artigo $4^{\circ}$, estabelecia a obrigatoriedade de $30 \%$ da carga horária do internato do curso de medicina ser dirigida à prática médica na APS e em serviços de urgência e emergência do SUS, e fixava o prazo de adequação dessa grade curricular para todas as escolas médicas até o ano de 2018. Em relação à estruturação da residência médica, com o PMM tornou-se obrigatória, a partir de 2018, a realização de um ano de residência em MFC para a formação profissional médica. Os autores destacam a relevância da mudança do perfil da formação profissional e o incentivo à interiorização dos médicos ${ }^{28}$.

Nesse sentido, a mudança nas Diretrizes Curriculares Nacionais (DCN) do curso de graduação de medicina ocasionou debates acalorados com as entidades médicas, visto que essas criticaram a obrigatoriedade da residência em MFC, com a consequente expansão de vagas para essa especialidade, alegando que tal orientação iria 
deteriorar a qualidade da formação de especialistas no país. Entretanto, um dos pontos destacados pelos defensores das ações propostas foi que essa expansão era necessária, não apenas para melhorar a qualificação do trabalho médico na APS, mas para inclusive substituir, no longo prazo, a atenção médica executada por profissionais não brasileiros ${ }^{29,30}$.

Nos dois primeiros anos de implementação do PMM, das vagas criadas na graduação de medicina, 32\% foram alocadas nas universidades públicas, $68 \%$ em instituições privadas, registrando a taxa nacional de vagas autorizadas por $10 \mathrm{mil}$ habitantes de 0,81 . Com relação à interiorização dos médicos, no Rio de Janeiro, por exemplo, a maioria das vagas autorizadas se concentrou nos municípios do interior fluminense, região mais carente de médicos, estando em conformidade, como observam, com os objetivos do programa ${ }^{28}$.

No Nordeste, a implantação de novos cursos de graduação em medicina revelou-se exitosa, sobretudo na interiorização das vagas e nas inovações pedagógicas realizadas, privilegiando a horizontalidade do processo de aprendizado, com a integração do graduando de medicina à rede de serviços em equipes multiprofissionais de saúde e à vivência na comunidade ${ }^{31}$. São citados os exemplos bem-sucedidos de Caicó (RN) ${ }^{11,12,32} \mathrm{e}$ as ações desenvolvidas no estado da Paraíba. Neste, destacou-se a interlocução contínua entre os vários atores coletivos envolvidos no processo de implementação, como o Conselho de Secretários Municipais de Saúde (COSEMS) e a coordenação do PMM, resultando numa extensa rede colaborativa entre ensino-serviço ${ }^{33}$.

Da mesma forma, deve-se apontar o incremento dos cursos de especialização ofertados pelo programa, privilegiando a educação interprofissional e a qualificação da prática médica voltada às necessidades de saúde das populações locais atendidas na APS ${ }^{34}$.

Apontando o fortalecimento da atenção básica, mas sobretudo do SUS, o estudo de Storti, Oliveira e Xavier ${ }^{35}$ buscou indicar estratégias para a criação ou expansão de vagas de seis programas de residência médica em MFC sob a coordenação de gestores municipais do SUS, que podem contribuir, no longo prazo, com o provimento de médicos, conforme previsto no PMM.

Os dados da pesquisa, de caráter qualitativo e exploratório, foram coletados a partir de duas oficinas ministradas pelo Ministério da Saúde, em 2015, dirigidas aos coordenadores e gestores municipais do Programa de Residência Médica de Medicina de Família e Comunidade.
Em linhas gerais, os achados dos autores indicam que os gestores de saúde podem impactar, de forma relevante, o incremento da formação médica em MFC. Por um lado, a articulação de iniciativas municipais, como o fortalecimento da integração entre ensino e serviço na rede de atenção à saúde do município, o aumento da cobertura da atenção básica e o aperfeiçoamento das Unidades Básicas de Saúde são estratégias potencializadoras da residência de Medicina de Família e Comunidade. Por outro, a parceria entre políticas federais e a gestão municipal, concernentes à coordenação entre educação e trabalho, como articulada no PMM, pode garantir a continuidade de qualificação médica nos serviços municipais, fortalecendo a atenção básica, a universalização do acesso e o próprio SUS. Todavia, alertam os autores, as conquistas alcançadas pelo PMM não ofuscam as críticas que apontam alguns de seus limites, como a característica privatizante da expansão da graduação médica, o caráter provisório do programa, a indefinição da carreira profissional, dentre outras ${ }^{35}$.

Também são apontadas críticas ao desconhecimento, por parte de estudantes e professores de medicina, desse eixo da implementação. Devido aos embates públicos e políticos gerados pelo provimento emergencial de médicos cubanos à APS, em grande medida acalentados e expostos pela mídia e pelas corporações profissionais médicas, o PMMB foi visto por segmentos da população e do meio acadêmico como o único objetivo do programa ${ }^{36}$. Da mesma forma, a invisibilidade desse eixo foi constatada entre gestores locais, dada a não uniformidade na implementação do programa no país ${ }^{16}$.

A alteração nas DCN para a graduação do curso de medicina possibilitou ao Estado, no âmbito da implementação do PMM, instrumentos para garantir a formação médica orientada à atenção das demandas de saúde pública, diferentemente do modelo anterior, conservador e voltado ao mercado ${ }^{37}$. Nesse sentido, o PMM propôs mudanças na prática médica, rompendo com o ideário social que tradicionalmente a concebe como atividade eminentemente especializada e biologizada. No longo prazo, esperava-se que tal alteração surtisse efeitos culturais, com a mudança do perfil profissional e da prática médica, o que se refletiria num trabalho mais humanizado e voltado à atenção integral à saúde dos cidadãos ${ }^{38}$.

Entretanto, os limites apontados para a implementação desse eixo, segundo alguns autores, espelham menos as possíveis deficiências do 
programa do que o contexto político atual do país ${ }^{16,39}$. Com a assunção do então novo governo federal em 2016, caracterizado politicamente como um rompimento do processo democrático até então vigente, o PMM foi descaracterizado de sua formulação original. A partir de 2017 houve a desidratação paulatina do programa, com o corte progressivo de recursos financeiros direcionados ao convênio entre os ministérios da Saúde e Educação, ocasionando a paralisação da supervisão acadêmica, da expansão dos cursos de graduação de medicina e de vagas para residência. A expansão das vagas da graduação de medicina atingiu $60 \%$ das metas ${ }^{37}$. Além disso, os apoiadores institucionais do PMM foram substituídos por outros, cujos perfis adotados obedecem mais a critérios burocráticos do que técnicos.

\section{Eixo Projeto Mais Médicos para o Brasil (PMMB) - provisionamento emergencial médico}

As análises sobre a implementação deste eixo apontam o impacto positivo do PMM na diminuição da escassez de médicos na APS em todo o país, principalmente nas regiões e localidades distantes, historicamente desvalidas de serviços médicos e de saúde. O estudo de Girardi e colaboradores ${ }^{6}$ informa que, antes da implementação do PMM, 20\% dos municípios brasileiros, sobretudo aqueles mais longínquos e pobres, padeciam com a carência de serviços médicos.

As regiões que mais receberam médicos vindos do PMMB, segundo evidencia o estudo, foram o Nordeste e o Sudeste, com 4.849 e 4.372 médicos, respectivamente. A região Norte registrou a maior participação de médicos do programa, $23,7 \%$, atendendo aos objetivos propostos quanto ao direcionamento de médicos para as áreas com maior carência de serviços médicos e de saúde ${ }^{20}$. Endossando pesquisa realizada pela Universidade de Brasília em munícipios pobres das cinco regiões da federação com usuários do SUS, profissionais de saúde e gestores, os autores apontam que, para estes últimos, a vinda dos médicos do PMMB agilizou e ampliou a capacidade de diagnósticos e tratamentos de problemas de saúde da população local, um dos fatores que contribuiu para que os usuários avaliassem positivamente $o$ programa, conforme revelou o estudo ${ }^{6}$.

A satisfação dos usuários é um dos temas enfatizados por Kemper, Mendonça e Souza ${ }^{14}$ na revisão bibliográfica crítica que realizaram sobre o PMM com 54 publicações, sendo 37 artigos e 17 trabalhos acadêmicos, com o objetivo de mapear a literatura científica acerca do tema. Em linhas gerais, indicam que os estudos têm mostrado que os usuários das UBS estão satisfeitos com o atendimento médico dos profissionais do programa. Fazem particular referência ao resultado de investigação realizada em 2014, pela Universidade Federal de Minas Gerais e pelo Instituto de Pesquisas Sociais, Políticas e Econômicas, em que 85\% dos usuários dos serviços médicos pós-implementação do PMMB avaliaram que o atendimento ficou "melhor" ou "muito melhor", 60\% indicaram como fatores positivos da mudança a presença contínua do médico e o cumprimento da carga horária e $46 \%$ expressaram contentamento com a melhoria no acesso às consultas.

Outro tema a se destacar da referida revisão diz respeito às práticas, às ações de saúde e à concepção ampliada do processo saúde-doença contemplada na análise da integralidade e longitudinalidade do PMM. As investigações apontam que o programa atua e se organiza a partir da perspectiva da atenção integral, ofertando ações e serviços que atendem desde a promoção da saúde até os cuidados paliativos, proporcionando maior proximidade e vínculo com os usuários, aspectos também observados nos estudos de Liz e Lima ${ }^{40}$ e Comes e colaboradores ${ }^{41}$. Em relação à continuidade dos cuidados ao longo do tempo (longitudinalidade) e à boa qualidade do vínculo estabelecido entre profissional e usuários, destaca-se a permanência do médico na equipe por períodos mais longos e a constituição de relações mais dialógicas entre ambas as partes ${ }^{17}$.

A ampliação do acesso à APS com a implementação do PMMB é ressaltada no estudo de Rech e colaboradores ${ }^{42}$ e endossada por Telles, Silva e Bastos ${ }^{43}$, sendo enfatizado por estes a satisfação dos usuários com o programa, que se relaciona ao aumento do número de médicos, à redução da espera por consultas e à rapidez e facilidade com que passaram a acessar os serviços.

O estudo de Pereira e Pacheco ${ }^{18}$ ilustra como o PMMB garantiu o princípio da equidade e integralidade em saúde em localidades distantes e empobrecidas. Trata-se de uma pesquisa qualitativa, realizada em município predominantemente rural no estado do Pará. Por meio de roteiro semiestruturado, entrevistaram 18 profissionais atuantes na Estratégia Saúde da Família, cinco gestores, quatro médicos do PMM, um representante do Conselho Municipal de Saúde e 14 usuários. $\mathrm{Na}$ análise da implementação do programa na localidade estudada, as autoras destacam a melhora sensível da APS, relacionada ao aumento de consultas e à ampliação do acesso dos usuários aos serviços ofertados pela UBS, 
possibilitados por estratégias mais equitativas no planejamento das ações de saúde.

Com relação à integralidade, princípio estruturante das práticas de Saúde ${ }^{23}$, evidenciou-se que os médicos do programa buscam dirigir sua prática profissional às especificidades da população rural, servindo-se de ações de educação em saúde, organização da agenda e planejamento das ações com a equipe. Segundo as autoras, houve incremento das visitas domiciliares e, conforme relatado pelos usuários e profissionais, o médico cubano se diferencia dos outros porque tende a respeitar a cultura dos moradores em sua prática clínica, estabelecendo uma relação mais dialógica com a clientela, como observado também em outros estudos $^{6,19}$, e dessa forma atendendo às necessidades peculiares de saúde das populações rurais e periféricas das grandes cidades.

Quanto a cobertura e qualificação dos médicos do PMMB, destaca-se a formação adequada para o exercício profissional na atenção básica, estando em constante processo de aprendizagem e devidamente integrada ao processo de educação-serviço ${ }^{18}$.

Sobre o aprendizado e qualificação constantes a que são submetidos os profissionais médicos do PMMB, referencia-se o artigo de Almeida e colaboradores $^{21}$, enfatizando a supervisão acadêmica, parceria entre os serviços de saúde e as universidades, em que é ofertado apoio pedagógico para a manutenção de habilidades e competências exigidas no trabalho na atenção básica. Ao longo de 2015 foram realizadas visitas aos serviços, atividades longitudinais de supervisão, além de encontros regionais tratando de temas condizentes à realidade das condições de saúde das populações atendidas, tais como atendimento às doenças crônico-degenerativas, doenças tropicais negligenciadas e saúde mental, abarcando ainda o processo de trabalho na atenção básica. Concluem os autores que a supervisão acadêmica no PMM têm se constituído em instrumento vigoroso de fortalecimento da atenção básica e qualificação profissional, expresso no estreitamento dos laços entre ensino-serviços-comunidade.

Referindo-se a cobertura e ampliação do acesso de populações historicamente desassistidas pelos serviços médicos e de saúde, Kemper, Mendonça e Sousa ${ }^{17}$ enfatizam que o PMM supriu 400 municípios que nunca contaram com tais serviços, especialmente entre os 34 Distritos Sanitários Especiais Indígenas, que chegaram a registrar a presença de 300 profissionais médicos, 99\% deles de origem cubana.

Para finalizar, são indicadas algumas críticas a este eixo de implementação do programa. De forma geral, se referem ao caráter provisório do programa, o que pode se configurar no curto prazo como modelo paliativo e de elevado custo, com os problemas da distribuição irregular de médicos nos serviços de saúde brasileiros retornando tão logo termine o programa. De um lado, aponta-se que esse problema é estrutural do SUS, exigindo medidas de longo prazo, com maiores investimentos na área de saúde, englobando tanto os aspectos estruturais quanto os recursos humanos. De outro, tais críticas vão ao encontro daquelas endereçadas à organização técnica do programa, como: a alocação de médicos em locais que, a rigor, não necessitam de mais médicos; a dependência gerada nos municípios em relação ao governo federal para suprimento de profissionais médicos; e a substituição de médicos contratados por médicos cooperados (estrangeiros) ${ }^{17}$.

\section{Considerações finais}

A análise dos estudos da implementação dos três eixos estruturantes do PMM pertinentes a esta revisão, permite constatar avanços e fragilidades do programa, concernentes ao acessoe à universalização da atenção.

Os estudos que analisam a melhoria da infraestrutura das redes de atenção básica à saúde, estruturante do eixo 1 do PMM, apontam a potencialidade que este tem de reduzir as iniquidades de saúde, sobretudo quando articulado a outros programas que visam fortalecer a atenção básica. Entretanto, como apontado, as regiões mais carentes de assistência médica ainda apresentam condições precárias para estruturação das APS. Este problema afeta o acesso, bem como os processos de trabalho em saúde, gerando descontinuidade da assistência médica e, na maioria dos casos, a não participação dos municípios em programas governamentais que subsidiam as melhorias requeridas.

A análise dos artigos referentes à implementação do eixo 2 do PMM, relativo à ampliação de vagas de cursos de medicina e reformas na educação médica, revelou que iniciativas e parcerias entre ensino e serviço por meio da gestão municipal podem potencializar a residência de MFC, bem como parcerias estratégicas entre os entes federados, fortalecendo a atenção básica e o SUS. No entanto, os estudos apontam a crescente privatização da graduação médica, o caráter provisório do programa e a indefinição profissional como fatores que tencionam negativamente a sua efetivação.

Revelou, ainda, que as mudanças propostas e reguladas pelo Estado encontraram barreiras fortemente estabelecidas pelas corporações mé- 
dicas. Tratava-se de mudar o perfil dos médicos, adequando-o às necessidades de saúde de grandes parcelas da população carentes de atenção médica.

Essa mudança é também cultural, na medida em que apenas no longo prazo o modelo conservador e voltado ao mercado, historicamente construído do exercício profissional médico, pode ser substituído, priorizando tanto o contato com a comunidade, com o outro que tem carências peculiares, como as relações horizontais e humanizadas. Nesse encontro, o processo saúde-doença-atenção-cuidado se estabelece como parceria entre médico e usuário do SUS, em que ambos são afetados pela interação social, ou seja, a mudança da prática médica também muda aqueles a quem se dirige a atenção, de forma positiva ou negativa, dependendo do modelo do exercício profissional adotado.

Referindo-se ao provimento emergencial médico, eixo 3 do programa, especificamente à prática médica dos estrangeiros participantes, sobretudo dos médicos cubanos, os estudos apontam a visão ampliada que estes têm do processo saúdedoença-cuidado, abarcando os determinantes sociais da saúde, as relações horizontais que estabelecem com a clientela, assim como a sensibilidade com relação às peculiaridades socioculturais que permeiam essas relações.

Observa-se com apreensão o desenvolvimento de políticas e programas de saúde empreen- didos pelo governo federal brasileiro eleito em 2018. No caso do PMMB, a postura unilateral estabelecida pelo atual governo, com vistas a alterar a cooperação já celebrada pelos governos brasileiros anteriores, comprometeu sobremaneira o atendimento médico nos municípios distantes e na periferia das grandes cidades, até então atendidos pelos médicos intercambistas.

Do ponto de vista da análise institucional, comumente considera-se que as políticas e os programas de saúde, como no caso do PMM, obedecem à lógica dialética decorrente do movimento de sua institucionalização, isto é, antes de ser instituído universalmente passa por um processo em que o instituinte $-o$ acontecimento que não cessa de alterar e até de negar o que está formalizado - se articula às práticas cotidianas dos sujeitos, tencionando-as. É esse movimento dialético atualizador das práticas que permite a manutenção ou a dissolução de um programa, não obstante previsto em lei ${ }^{44}$.

A carência de médicos nestas regiões e localidades volta, novamente, a ser um entrave para o desenvolvimento da equidade em saúde, uma vez que as populações historicamente vulneráveis pretos, pobres, quilombolas, indígenas, das regiões Norte, Nordeste e Centro-Oeste do país e das periferias das grandes cidades - são as que mais sofrem com essa carência.

\section{Colaboradores}

MA Separavich: contribuiu na concepção e planejamento do trabalho, na coleta de informações, análise e interpretação dos dados, elaboração do texto e revisão crítica do conteúdo. MT Couto: contribuiu na concepção e planejamento do trabalho e na revisão crítica das versões inicial e final do manuscrito.

\section{Agradecimentos}

Os autores agradecem ao apoio financeiro concedido pelo Conselho Nacional de Desenvolvimento Científico e Tecnológico $(\mathrm{CNPq})$, referente à concessão de bolsa de pós-doutorado para a realização do projeto Vozes estrangeiras no Mais Médicos: interseccionalidade de gênero, classe e raçal etnia de profissionais do Programa Mais Médicos em Campinas, SP. 


\section{Referências}

1. Scheffer M, organizador. Demografia médica no Brasil 2018. São Paulo: FMUSP, CFM, Cremesp; 2018.

2. Organização Pan-Americana da Saúde. Relatório 30 anos de SUS, que SUS para 2030? Brasília: OPAS; 2018.

3. Lei $\mathrm{n}^{\circ} 12.871$, de 22 de outubro de 2013. Institui o Programa Mais Médicos, altera as Leis no 8.745 , de 9 de dezembro de 1993, e no 6.932, de 7 de julho de 1981, e dá outras providências. Brasília (DF): Diário Oficial da União 2013; 23 out. [acessado em set. 2015]. Disponível em: http://pesquisa.in.gov.br/imprensa.

4. Carvalho MS, Sousa MF. Como o Brasil tem enfrentado o tema provimento médico? Interface (Botucatu) 2013; 17(47):913-926.

5. Franco CM, Almeida PF, Giovanella L. A integralidade das práticas dos médicos cubanos no Programa Mais Médicos na cidade do Rio de Janeiro, Brasil. Cad Saude Publica 2018; 34(9):e00102917.

6. Girardi SN, Stralen ACSV, Cella JN, Maas LWD, Carvalho CL, Faria EO. Impacto do Programa Mais Médicos na redução da escassez de médicos em atenção primária à saúde. Cien Saude Colet 2016; 21(9):26752684.

7. Lima RTS, Fernandes TG, Balieiro AAS, Costa FS, Scharamm JMA, Schweickardt JC, Ferla AA. A Atenção Básica no Brasil e o Programa Mais Médicos: uma análise de indicadores de produção. Cien Saude Colet 2016; 21(9):2685-2596.

8. Oliveira JPA, Sanchez NM, Santos LMP. O Programa Mais Médicos: provimento de médicos em municípios brasileiros prioritários entre 2013 e 2014 . Cien Saude Colet 2016; 21(9): 2719-2727.

9. Herval AM, Rodrigues ET. Ampliação do acesso e mudança de modelo: experiência a partir do Programa Mais Médicos. Interface (Botucatu) 2017; 21(Supl.):1325-1332.

10. Girardi SN, Carvalho CL, Pierantoni CR, Costa JO, Stralen ACSV, Lauar TV, David RB. Avaliação do escopo de prática de médicos participantes do Programa Mais Médicos e fatores associados. Cien Saude Colet 2016; 2(9) 1:2739-2748.

11. Melo LP, Santos M, Câmara RBG, Braga LP, Oliveira ALO, Pinto TR, Costa PM, Azevedo GD. A Escola Multicampi de Ciências Médicas da Universidade Federal do Rio Grande do Norte, Brasil, no contexto do Programa Mais Médicos: desafios e potencialidades. Interface (Botucatu) 2017; 21(Supl.): 1333-1343.

12. Oliveira ALO, Melo LP, Pinto TR, Azevedo GD, Santos M, Câmara RBG, Costa PM, Mata ANS. Vivência integrada na comunidade: inserção longitudinal no Sistema de Saúde como estratégia de formação médica. Interface (Botucatu) 2017; 21(Supl.):1355-1366.

13. Campos GWS, Pereira Junior N. A Atenção Primária e o Programa Mais Médicos do Sistema Único de Saúde: conquistas e limites. Cien Saude Colet 2016; 21(9):2655-2663.

14. Medina MG, Almeida PF, Lima JG, Moura D, Giovanella L. Programa Mais Médicos: mapeamento e análise da produção acadêmica no período 2013-2016 no Brasil. Saúde debate 2018; 42(n. esp.):346-60.

15. Granma. Havana: Órgão Oficial do Comitê Central do Partido Comunista de Cuba; 2018 [página na Internet]. [acessado 2018 Out 20]. Disponível em: http://pt.granma.cu/cuba/2018-11-14/declaracaodo-ministerio-da-saude-publica.
16. Santos MLM, Bertussi DC, Kodjaoglanian VL, Merhy EE. O que pode uma política? Problematizando a implementação do Programa Mais Médicos a partir da experiência de uma cidade brasileira. Interface (Botucatu) 2019; 23:e190052

17. Kemper ES, Mendonça AVM, Sousa MF. Programa Mais Médicos: panorama da produção científica. Cien Saude Colet 2016; 21(9):2785-2796.

18. Pereira LL, Pacheco L. O desafio do Programa Mais Médicos para o provimento e a garantia da atenção integral à saúde em áreas rurais na região amazônica, Brasil. Interface (Botucatu) 2017; 21(Supl.):11811192.

19. Soares AM, Furtado JP. O cuidado nutricional por estrangeiros no Projeto Mais Médicos para o Brasil. Interface (Botucatu) 2017; 21(Supl.):1229-1240.

20. Nogueira PTA, Bezerra AFB, Leite AFB, Carvalho IMS, Gonçalves RF, Silva KSB. Características da distribuição de profissionais do Programa Mais Médicos nos estados do Nordeste, Brasil. Cien Saude Colet 2016; 21(9): 2889-2898.

21. Almeida ER, Martins AF, Macedo HM, Penha RC Projeto Mais Médicos para o Brasil: uma análise da Supervisão Acadêmica. Interface (Botucatu) 2017; 21(Supl.): 1291-1300.

22. Lotta GS, Galvão MCCP, Favareto AS. Análise do Programa Mais Médicos à luz dos arranjos institucionais: intersetorialidade, relações federativas, participação social e territorialidade. Cien Saude Colet 2016; 21(9): 2761-2772.

23. Pinheiro R, Ferla A, Silva Junior AG. Integrality in the population's health care programs. Cien Saude Colet 2007; 12(2):343-349.

24. Soares Neto JJ, Machado MH, Alves CB. O Programa Mais Médicos, a infraestrutura das Unidades Básicas de Saúde e o Índice de Desenvolvimento Humano Municipal. Cien Saude Colet 2016; 21(9):2709-2718.

25. Pinto HÁ, Oliveira FP, Santa JSS, Santos FOS, Araújo SQ, Figueiredo AM, Araújo GD. Programa Mais Médicos: avaliando a implantação do Eixo Provimento de 2013 a 2015. Interface (Botucatu) 2017; 21(Supl.):1087-1101.

26. Giovanella L, Mendonça MHM, Fausto MCR, Almeida PF, Bousquat A, Lima JG, Seidl H, Franco CM, Fusaro ER, Almeida SZF. A provisão emergencial de médicos pelo Programa Mais Médicos e a qualidade da estrutura das unidades básicas de saúde. Cien Saude Colet 2016; 21(9):2697-2708.

27. Comes Y, Trindade JS, Shimizu HE, Hamann EM, Bargioni F, Ramirez L, Sanchez MN, Santos LMP. Avaliação da satisfação dos usuários e da responsividade dos serviços em municípios inscritos no Programa Mais Médicos. Cien Saude Colet 2016; 21(9):2749-2759.

28. Silva Jr AG, Andrade HS. Formação médica no Programa Mais Médicos: alguns riscos. Cien Saude Colet 2016; 21(9):2670-2671.

29. Oliveira FP, Santos LMP, Shimizu HE. Programa Mais Médicos e Diretrizes Curriculares Nacionais: avanços e fortalecimento do Sistema de Saúde. Trab Educ Saude 2019; 17:e0018415 
30. Oliveira FP, Araújo CA, Torres OM, Figueiredo AM, Souza PA, Oliveira FA, Alessio MM. O Programa Mais Médicos e o reordenamento da formação da residência médica com enfoque na Medicina de Família e Comunidade. Interface (Botucatu) 2019; 23(Supl.): e180008

31. Alencar VP, Guimaraes MAS, Mucari TB. Imersão na realidade: o Sistema Único de Saúde e a organização do Programa Mais Médicos em São Paulo, Brasil. Interface (Botucatu) 2017; 21(Supl.):1315-1324.

32. Sordi MRL, Cyrino EG, Mendonça CS. A história da expansão recente das escolas médicas no Brasil: uma conversa sobre educação, inovação e compromisso com o Sistema Único de Saúde (SUS). Interface (Botucatu) 2019; 23(Supl.):e190106

33. Barrêto DS, MeloNeto AJ, Figueiredo AM, Sampaio J, Gomes LB, Soares RS. Programa Mais Médicos e residências de Medicina de Família e Comunidade: estratégias articuladas de ampliação e interiorização da formação médica. Interface (Botucatu) 2019; 23(Supl.):e180032

34. Freire Filho JR, Magnago C, Costa MV, Forster AC. Cursos de especialização ofertados no âmbito do Mais Médicos: análise documental na perspectiva da Educação Interprofissional. Interface (Botucatu) 2018; 22(Supl.):1613-1624.

35. Storti MMT, Oliveira FP, Xavier AL. A expansão de vagas de residência de Medicina de Família e Comunidade por municípios e o Programa Mais Médicos. Interface (Botucatu) 2017; 21(Supl.): 1301-1313.

36. Villa Real GGO, Succi GM, Montalli VAM, Succi RCM. Estudantes e professores da área de saúde conhecem o Programa Mais Médicos? Rev Bras Educ Med 2017; 41(1):110-116.

37. Pinto HA, Andreazza R, Ribeiro RJ, Loula MR, Reis AAC. O Programa Mais Médicos e a mudança do papel do Estado na regulação e ordenação da formação médica. Interface (Botucatu) 2019; 23(supl.): e170960

38. Silva MP, Paraíso MA. Um currículo na integração ensino-serviço do Programa Mais Médicos e possíveis efeitos culturais. Trab Educ Saude 2019; 17(3):e0022454
39. Almeida ER, Macedo HM, Silva JC. Gestão federal do Programa Mais Médicos: o papel do Ministério da Educação. Interface (Botucatu) 2019; 23(Supl.): e180011

40. Liz RG, Lima RCGS. Percepções de usuários sobre o impacto social do projeto de cooperação do Programa Mais Médicos: um estudo de caso. Interface (Botucatu) 2017; 21(Supl.):1281-1290.

41. Comes Y, Trindade JS, Pessoa VM, Barreto ICHC, Shimizu HE, Dewes D, Arruda CAM, Santos LMP. A implementação do Programa Mais Médicos e a integralidade nas práticas da Estratégia Saúde da Família. Cien Saude Colet 2016; 21(9): 2729-2738.

42. Rech MRA, Hauser L, Wollmann L, Roman R, Mengue SS, Kemper SE, Florencio ASR, Alfaro G, Tasca R, Harzheim E. Qualidade da atenção primária no Brasil e associação com o Programa Mais Médicos. Rev Panam Salud Publica 2018; 42:e164.

43. Telles, H, Silva ALA, Bastos C. Programa Mais Médicos do Brasil: a centralidade da relação médico-usuário para a satisfação com o programa. Cad CRH 2019; 32:101-123.

44. L'Abbate S. Análise Institucional e Educação em Saúde: um diálogo produtivo. BIS 2004; 34:6-9.

Artigo apresentado em 11/11/2019

Aprovado em 07/04/2020

Versão final apresentada em 09/04/2020

Editores-chefes: Romeu Gomes, Antônio Augusto Moura da Silva 